\title{
A novel HAND2 loss-of-function mutation responsible for tetralogy of Fallot
}

\author{
CAI-XIA LU ${ }^{1 *}$, HAI-RONG GONG ${ }^{1 *}$, XING-YUAN LIU ${ }^{2 *}$, JUAN WANG $^{3}$, CUI-MEI ZHAO ${ }^{3}$, \\ RI-TAI HUANG ${ }^{4}$, SONG XUE $^{4}$ and YI-QING YANG ${ }^{5-7}$
}

${ }^{1}$ Department of Pediatrics, Huashan Hospital North, Fudan University, Shanghai 201907;

Departments of ${ }^{2}$ Pediatrics and ${ }^{3}$ Cardiology, Tongji Hospital, Tongji University School of Medicine, Shanghai 200065;

${ }^{4}$ Department of Cardiovascular Surgery, Renji Hospital, School of Medicine, Shanghai Jiao Tong University, Shanghai 200127;

Departments of ${ }^{5}$ Cardiology, ${ }^{6}$ Cardiovascular Research Laboratory and ${ }^{7}$ Central Laboratory,

Shanghai Chest Hospital, Shanghai Jiao Tong University, Shanghai 200030, P.R. China

Received September 1, 2015; Accepted December 2, 2015

DOI: $10.3892 /$ ijmm.2015.2436

\begin{abstract}
Congenital heart disease (CHD), the most common type of developmental abnormality, is associated with substantial morbidity and mortality in humans worldwide. The basic helix-loop-helix transcription factor, heart and neural crest derivatives expressed 2 (HAND2), has been demonstrated to be crucial for normal cardiovascular development in animal models. However, whether a genetically defective HAND2 contributes to congenital heart disease (CHD) in humans remains to be explored. In this study, the entire coding region and splicing boundaries of the HAND2 gene were sequenced in a cohort of 145 unrelated patients with CHD. A total of 200 unrelated, ethnically-matched healthy individuals used as controls were also genotyped for HAND2. The functional effect of the mutant HAND2 was characterized in contrast to its wild-type counterpart by using a dual-luciferase reporter assay system. As a result, a novel heterozygous HAND2 mutation, p.L47P, was identified in a patient with tetralogy of Fallot (TOF). The misense mutation, which altered the amino acid conserved evolutionarily among species, was absent in 400 control chromosomes. Functional analyses unveiled that the mutant HAND2 had a significantly decreased transcriptional activity. Furthermore, the mutation markedly reduced
\end{abstract}

Correspondence to: Dr Xing-Yuan Liu, Department of Pediatrics, Tongji Hospital, Tongji University School of Medicine, 389 Xincun Road, Shanghai 200065, P.R. China

E-mail: xingyuanliu69@163.com

Dr Yi-Qing Yang, Department of Cardiology, Shanghai Chest Hospital, Shanghai Jiao Tong University, 241 West Huaihai Road, Shanghai 200030, P.R. China

E-mail: dryyq@tongji.edu.cn

*Contributed equally

Key words: congenital heart disease, tetralogy of Fallot, genetics, transcription factor, HAND2, biological analysis the synergistic activation between HAND2 and GATA4 or NKX2.5, other two cardiac key transcription factors involved in the pathogenesis of CHD. To the best of our knowledge, this study is the first to report the association of a HAND2 lossof-function mutation with an increased vulnerability to TOF in humans, which provides novel insight into the molecular mechanism underpinning CHD, suggesting potential implications for the genetic counseling of families with CHD.

\section{Introduction}

Congenital heart disease (CHD) represents the most common form of birth defect, accounting for approximately one-third of all major congenital abnormalities, and each year, approximately 1.35 million infants are born with CHD worldwide (1). The estimated prevalence of CHD is $1 \%$ in live births, and up to $10 \%$ in stillbirths (2-4). In terms of specific anatomic or hemodynamic lesions, various CHDs are clinically classified into at least 21 distinct categories, including ventricular septal defect, atrial septal defect, endocardial cushion defect, tetralogy of Fallot (TOF), Ebstein's anomaly, double outlet of right ventricle, transposition of the great arteries, patent ductus arteriosus, persistent truncus arteriosus, coarctation of the aorta, aortic stenosis, pulmonary atresia, tricuspid atresia, interrupted aortic arch, total anomalous pulmonary venous connection and hypoplastic left heart syndrome, of which TOF is the most common type of cyanotic CHD, accounting for approximately $10 \%$ of all CHD cases (4). Severe CHD may give rise to a diminished quality of life, decreased exercise performance, retarded fetal brain development, depression, infective endocarditis, thromboembolism, pulmonary arterial hypertension, Eisenmenger's syndrome, heart failure, arrhythmias and even death (4-11). Hence, CHD is responsible for substantial morbidity and mortality, which lays a heavy economic burden on patients and health care systems (4). Despite important clinical significance, the etiologies of CHD remain largely unknown.

Cardiogenesis from the early embryo to the formation of a fully functional four-chambered heart is a complex and dynamic process that necessitates a harmonious concerto of transcription factors, adhesion molecules, ion channels, 
signaling molecules and structural proteins, and both environmental and genetic risk factors may disrupt this biological process of heart development, resulting in a wide variety of CHDs (12). Although environmental exposures are also relevant, a growing number of studies have demonstrated that genetic defects are the leading cause of CHD, and thus far, mutations in $>60$ genes have been causally linked to CHD (13-25). Among these CHD-causative genes, those encoding cardiac transcription factors, including homeodomain-containing protein, NK2 homeobox 5 (NKX2.5), GATA-binding protein 4 (GATA4) and T-box transcription factor 5 (TBX5), are the most commonly involved genes in the pathogenesis of CHD, underscoring the pivotal roles of cardiac transcription factors in cardiovascular development and disease (26).

The basic helix loop helix family of transcription factors, including heart and neural crest derivatives expressed (HAND)1 and HAND2, the only two members identified up to now, has been substantiated to be essential for normal cardiovascular development, with either Hand1- or Hand2-deficient mice not surviving due to cardiovascular developmental abnormalities (27). In humans, gain- or loss-of-function mutations in HAND1 have been associated with various CHDs, encompassing hypoplastic left heart syndrome, ventricular septal defect, atrial septal defect and atrioventricular septal defect (28-30). Considering that the expression profiles and functional roles of HAND2 overlap at least in proportion to those of HANDI (27,31-35), we hypothesized that genetically compromised HAND2 may contribute to the development of CHD in a subset of patients.

\section{Materials and methods}

Study subjects. A total of 145 unrelated patients with CHD were enrolled in this study. The available family members of the index patient who carried an identified HAND mutation were also included. A total of 200 unrelated individuals without CHD, who were matched to the CHD patients in ethnicity and gender, were recruited as the controls. All the study subjects were from the Han Chinese population. They underwent a comprehensive clinical evaluation, including medical history, physical examination, transthoracic echocardiography, standard 12-lead electrocardiogram and chest X-ray radiography. The clinical types of CHD were defined with two-dimensional continuous wave Doppler and color Doppler techniques on transthoracic echocardiography. When indicated, transesophageal echocardiography, cardiac catheterization and angiography were performed to further clarify the cardiovascular anatomic malformations. Cardiac surgery was carried out in some of the patients with CHD. The patients who suffered from chromosomal abnormalities or syndromic cardiovascular anomalies, such as Axenfeld-Rieger syndrome, DiGeorge syndrome, Alagille syndrome and Holt-Oram syndrome, were excluded from the current study. This study is in conformity with the principles of the Declaration of Helsinki. The study protocol was reviewed and approved by the Ethics Committee of Tongji Hospital, Tongji University, Shanghai, China (ethical approval number for cases and controls: LL(H)-09-07; date of approval: July 27, 2009). Written informed consent was obtained from the participants or their guardians prior to the commencement of the study.
Genetic analysis of HAND2. Whole blood samples from the patients with CHD and the control individuals were collected. Genomic DNA was isolated from blood leukocytes using the Wizard Genomic DNA purification kit (Promega, Madison, WI, USA), according to the manufacture's instructions. With the aid of online Primer 3 (http://primer3.ut.ee), the primers used for the amplification of the coding exons and flanking introns of HAND2 by polymerase chain reaction (PCR) were designed as shown in Table I. The referential genomic DNA sequence of HAND2 was from GenBank (accession no. NC_000004). PCR was conducted using a standard procedure on a Veriti Thermal Cycler (Applied Biosystems, Foster City, CA, USA). Basically, a PCR mixture consisted of $1 \mathrm{X}$ PCR buffer, $1 \mathrm{X}$ Q solution, 5 pmol of each primer pairs, $0.2 \mathrm{mM}$ dNTPs, $50 \mathrm{ng}$ of genomic DNA and 1 unit of HotStar TaqDNA polymerase (Qiagen, Hilden, Germany), to a volume of $25 \mu 1$ with double distilled water. A typical PCR program was an initial activation of the polymerase (Qiagen) at $95^{\circ} \mathrm{C}$ for $15 \mathrm{~min}$, followed by 35 cycles of denaturation at $94^{\circ} \mathrm{C}$ for $30 \mathrm{sec}$, annealing at $62^{\circ} \mathrm{C}$ for $1 \mathrm{~min}$, and elongation at $72^{\circ} \mathrm{C}$ for $1 \mathrm{~min}$, with a final extension at $72^{\circ} \mathrm{C}$ for $6 \mathrm{~min}$. The PCR-amplified fragments were purified and sequenced with $H A N D 2$-specific primers using the BigDye ${ }^{\circledR}$ Terminator v3.1 Cycle Sequencing kit on an ABI PRISM 3130 XL DNA Analyzer (both from Applied Biosystems). For an identified mutation in the coding region of HAND2, the numbering of it started with the nucleotide $\mathrm{A}$ of the initial translation codon ATG (accession no. NM_021973.2). To confirm the novelty of an identified sequence variation, the single nucleotide polymorphism (SNP; http://www.ncbi.nlm. nih.gov/SNP) database, the human genome mutation database (HGMD; http://www.hgmd.org/), the 1000 genomes project database (1000 Genomes; http://www.1000genomes.org) and the exome variant server (EVS; http://evs.gs.washington. edu/EVS) database were queried.

Alignment of multiple amino acids of HAND2 proteins across species. The amino acids of HAND2 proteins from various species were aligned with the online MUSCLE program (http:// www.ncbi.nlm.nih.gov/homologene?cmd=Retrieve\&dopt=Mul tipleAlignment\&list_uids=32092).

In silico analysis of HAND2 mutation. The functional consequence of an identified sequence variation on HAND2 protein was predicted by MutationTaster (http://www.mutationtaster. org/), PolyPhen-2 (http://genetics.bwh.harvard.edu/pph2/) and SIFT (http://sift.jcvi.org).

Expression plasmids and site-directed mutagenesis. The human cardiac full-length cDNA was prepared as previously described $(22,23,36-38)$. Human HAND2 harboring the whole coding region was generated by PCR with the human heartcDNA as a template, cut with the restriction enzymes, EcoRI and NotI, and then subcloned at the EcoRI-NotI sites of the pcDNA3.1 vector (Invitrogen, Carlsbad, CA, USA). The identified mutation was introduced into the wild-type HAND2-pcDNA3.1 construct by site-directed mutagenesis using a complementary pair of primers and the QuickChange II XL Site-Directed Mutagenesis kit (Stratagene, La Jolla, CA, USA), and verified by direct sequencing. The recombinant expression plasmids GATA4-pSSRa and NKX2.5-pEFSA, and the ANF-luciferase 
Table I. Primers to amplify the coding exons and flanking introns of the HAND2 gene.

\begin{tabular}{|c|c|c|c|}
\hline Coding exon & Forward primer & Reverse primer & Amplicon size (bp) \\
\hline $1-\mathrm{a}$ & 5'-cgagaggattctgcetccgc-3' & 5'-acagggccatgctgtagtcg-3' & 550 \\
\hline $1-b$ & $5^{\prime}$-ggtaggtggttttccccacca-3' & $5^{\prime}$-gcccaattggaaagaggccg-3' & 624 \\
\hline 2 & $5^{\prime}$-ggttcactgtctcctccggc-3' & $5^{\prime}$-cgggatcccttaccacacgg-3' & 483 \\
\hline
\end{tabular}

bp, base pairs.

Table II. Baseline clinical characteristics of the study patients with CHD ( $=145)$.

\begin{tabular}{|c|c|}
\hline Variables & Statistics \\
\hline Age (years) & $3.68 \pm 1.52$ \\
\hline Male $(\%)$ & $78(54)$ \\
\hline Positive family history of CHD (\%) & $6(4)$ \\
\hline \multicolumn{2}{|l|}{ Distribution of different types of CHD } \\
\hline Isolated CHD (\%) & $93(64)$ \\
\hline $\operatorname{VSD}(\%)$ & $32(22)$ \\
\hline $\operatorname{ASD}(\%)$ & $26(18)$ \\
\hline PDA $(\%)$ & $12(8)$ \\
\hline DORV $(\%)$ & $5(3)$ \\
\hline $\operatorname{ECD}(\%)$ & $4(3)$ \\
\hline PTA $(\%)$ & $4(3)$ \\
\hline Other isolated CHD (\%) & $10(7)$ \\
\hline Complex CHD (\%) & $52(36)$ \\
\hline TOF $(\%)$ & $25(17)$ \\
\hline $\mathrm{ASD}+\mathrm{VSD}(\%)$ & $8(6)$ \\
\hline VSD + DORV (\%) & $5(3)$ \\
\hline VSD + AS (\%) & $4(3)$ \\
\hline VSD + TGA (\%) & $3(2)$ \\
\hline Other complex CHD (\%) & $7(5)$ \\
\hline \multicolumn{2}{|l|}{ Arrhythmias } \\
\hline Cardiac conduction block (\%) & $6(4)$ \\
\hline Atrial fibrillation $(\%)$ & $3(2)$ \\
\hline \multicolumn{2}{|l|}{ Treatment } \\
\hline Cardiac surgery $(\%)$ & $67(46)$ \\
\hline Catheter-based repair (\%) & $46(32)$ \\
\hline Follow-up (\%) & $32(22)$ \\
\hline
\end{tabular}

Data are expressed as the means \pm standard deviation, number or percentage. CHD, congenital heart disease; VSD, ventricular septal defect; ASD, atrial septal defect; PDA, patent ductus arteriosus; DORV, double outlet right ventricle; ECD, endocardial cushion defect; PTA, persistent truncus arteriosus; TOF, tetralogy of Fallot; AS, aortic stenosis; TGA, transposition of the great arteries.

(ANF-luc) reporter plasmid, which contains 2,600 base pairs upstream of the transcriptional start site of the $A N F$ gene and expresses Firefly luciferase, were generously provided by Dr Ichiro Shiojima from Chiba University School of Medicine, Chiba, Japan.
Cell culture and luciferase reporter assays. HeLa cells (from a cell bank of our cardiovascular research laboratory) were cultured in Dulbecco's modified Eagle's medium supplemented with $10 \%$ fetal bovine serum, $2 \mathrm{mM}$ glutamine, $100 \mu \mathrm{g} / \mathrm{ml}$ of penicillin and $100 \mu \mathrm{g} / \mathrm{ml}$ of streptomycin in an atmosphere of $5 \% \mathrm{CO}_{2}$ at $37^{\circ} \mathrm{C}$. Cell transfection was carried out in 6 -well plates using Lipofectamine ${ }^{\circledR} 2000$ reagent (Invitrogen) $24 \mathrm{~h}$ after plating. The internal control plasmid, pGL4.75 (hRluc/CMV; Promega), which expresses Renilla luciferase, was used in the transfection assays to normalize the transfection efficiency. In the transient transfection of HeLa cells, the same amount $(0.6 \mu \mathrm{g})$ of plasmid DNA (wild-type HAND2-pcDNA3.1, mutant HAND2pcDNA3.1, GATA4-pSSRa or NKX2.5-pEFSA) was used alone or in combination, in the presence of $1.0 \mu \mathrm{g}$ of ANF-luc and $0.04 \mu \mathrm{g}$ of pGL4.75. The cells were lysed $48 \mathrm{~h}$ after transfection, and the Firefly and Renilla luciferase activities were measured using the Dual-Glo luciferase assay system (Promega) according to the manufacturer's instructions. The activity of the $A N F$ promoter was expressed as the fold activation of Firefly luciferase relative to Renilla luciferase. Three independent experiments were performed in triplicate for each cell transfection, and each value presented was the average of triplicate samples.

Statistical analysis. Continuous data are expressed as the means \pm standard deviation (SD). Differences in continuous variables between 2 groups were compared using the Student's unpaired t-test. Differences in categorical variables between 2 groups were compared using the $\chi^{2}$ test or Fisher's exact test, as indicated. The significance level was set at a two-tailed P-value of $<0.05$. All statistical analyses were performed with SPSS version 18.0 (SPSS IBM, New York, NY, USA).

\section{Results}

Clinical characteristics of the study participants. In this study, 145 unrelated patients with CHD were clinically investigated in contrast to 200 unrelated control individuals without CHD. All the patients with CHD had congenital cardiac defects confirmed by an echocardiogram or further by cardiac surgery. Based on the medical histories and echocardiographic records, the control individuals had neither CHD nor a positive family history of CHD. There were no differences in ethnicity, gender and age between the patient and control groups. The baseline clinical characteristics of the study patients with CHD are presented in Table II.

Identification of a novel mutation in HAND2. By direct PCR-sequencing of the HAND2 gene in the 145 unrelated 


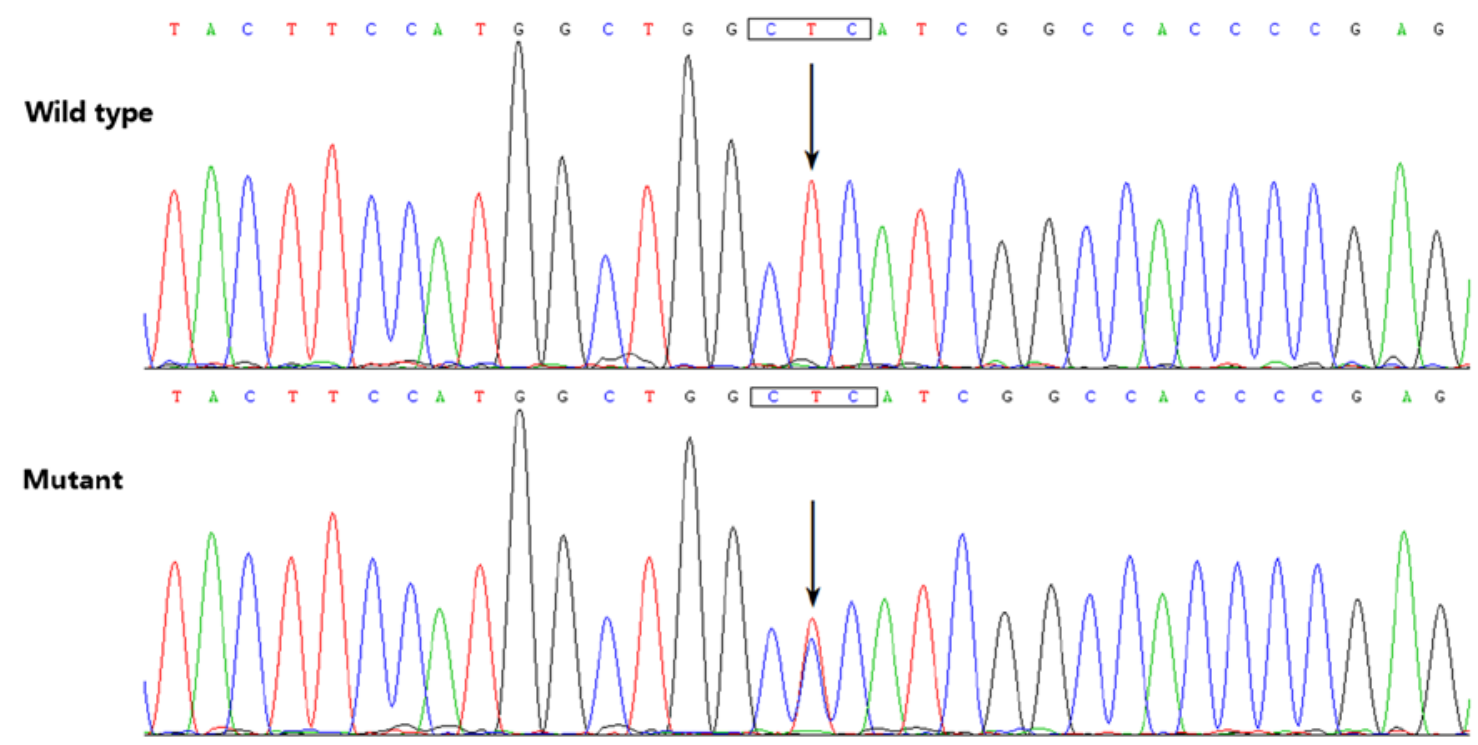

Figure 1. Sequence electropherograms displaying the heterozygous HAND2 mutation and its wild-type control. The arrow indicates the heterozygous nucleotides of T/C in the patient with tetralogy of Fallot (mutant) or the homozygous nucleotides of T/T in the corresponding control subject (wild-type). The rectangle marks the nucleotides that comprise a codon of HAND2.

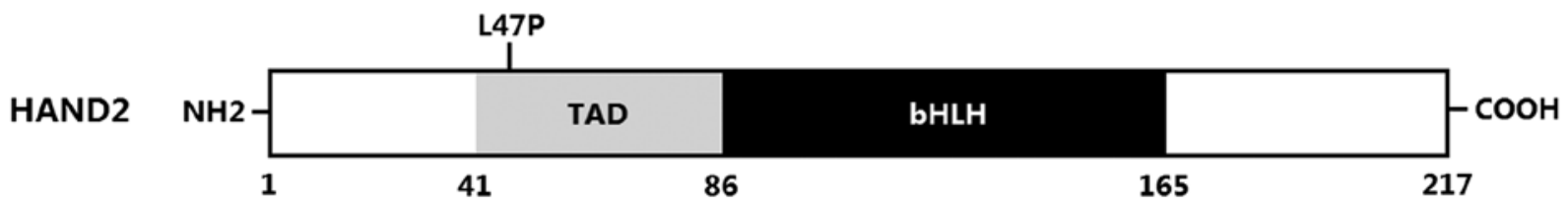

Figure 2. Schematic diagram depicting the structural domains of HAND2. The mutation identified in the patient with tetralogy of Fallot is shown above the structural domains. NH2, amino-terminus; TAD, transcriptional activation domain; bHLH, basic helix-loop-helix; COOH, carboxyl-terminus.

patients with CHD, a transition of thymine to cytosine in the second nucleotide of codon 47 (c.140T $>$ C), predicting the substitution of proline at amino acid position 47 for leucine (p. L47P), was identified in a male patient with TOF, who was half a year old without a positive family history of CHD. Additionally, sequence analysis of HAND2 in the parents of the mutation carriers revealed no mutation, indicating that the identified mutation was a de novo mutation. The DNA sequencing electropherograms showing the identified heterozygous HAND2 mutation of c.140T $>\mathrm{C}$ in comparison with its control sequence are shown in Fig. 1. A schematic diagram of HAND2 depicting the functionally important structural domains and the location of the mutation detected in this study is presented in Fig. 2. The missense mutation was neither observed in the 200 control individuals nor found in the SNP, HGMD, 1000 Genomes and EVS databases.

Alignment of multiple amino acids of HAND2 proteins from various species. Alignment of the amino acids of the human HAND2 protein with those of chimpanzee, monkey, dog, cattle, mouse, rat, zebrafish and frog exhibited that the altered leucine at amino acid residue 47 of human HAND2 was completely conserved evolutionarily (Fig. 3).

Causative potential of the identified HAND2 sequence variation. The HAND2 sequence variation of $\mathrm{c} .140 \mathrm{~T}>\mathrm{C}$ was predicted to be disease-causing by MutationTaster, with a
P-value of 1.0000 , probably damaging by PolyPhen-2, with a score of 0.999 (sensitivity 0.14 ; specificity 0.99 ) and intolerated by SIFT, with a score of 0.02 .

Functional impairment of the HAND2 protein caused by the mutation. As shown in Fig. 4, the same amount $(0.6 \mu \mathrm{g})$ of wildtype and L47P-mutant HAND2 transcriptionally activated the ANF promoter by $\sim 8$ - and 2-fold, respectively (wild-type vs. mutant, $\mathrm{t}=5.6462, \mathrm{P}=0.0048)$. In the presence of $0.6 \mu \mathrm{g}$ of wild-type GATA4, the same amount $(0.6 \mu \mathrm{g})$ of wild-type and L47P-mutant HAND2 activated the $A N F$ promoter by $\sim 35$ - and 14-fold, respectively (wild-type vs. mutant, $\mathrm{t}=10.3947$, $\mathrm{P}=0.0005$ ); while in the presence of $0.6 \mu \mathrm{g}$ of wild-type $N K X 2.5$, the same amount $(0.6 \mu \mathrm{g})$ of wild-type and L47P-mutant HAND2 activated the ANF promoter by $\sim 24$ - and 11-fold, respectively (wild-type vs. mutant, $\mathrm{t}=8.5137, \mathrm{P}=0.0010$ ). These results reveal that the L47P-mutant HAND2 has a significantly reduced transcriptional activity, and furthermore, the mutation markedly diminishes the synergistic activation between HAND2 and GATA4 or between HAND2 and NKX2.5.

\section{Discussion}

TOF, characterized by four distinct anatomic features, including pulmonary outflow tract obstruction, overriding aortic root, ventricular septal defect and right ventricular hypertrophy, constitutes approximately $7-10 \%$ of all CHD cases, corre- 


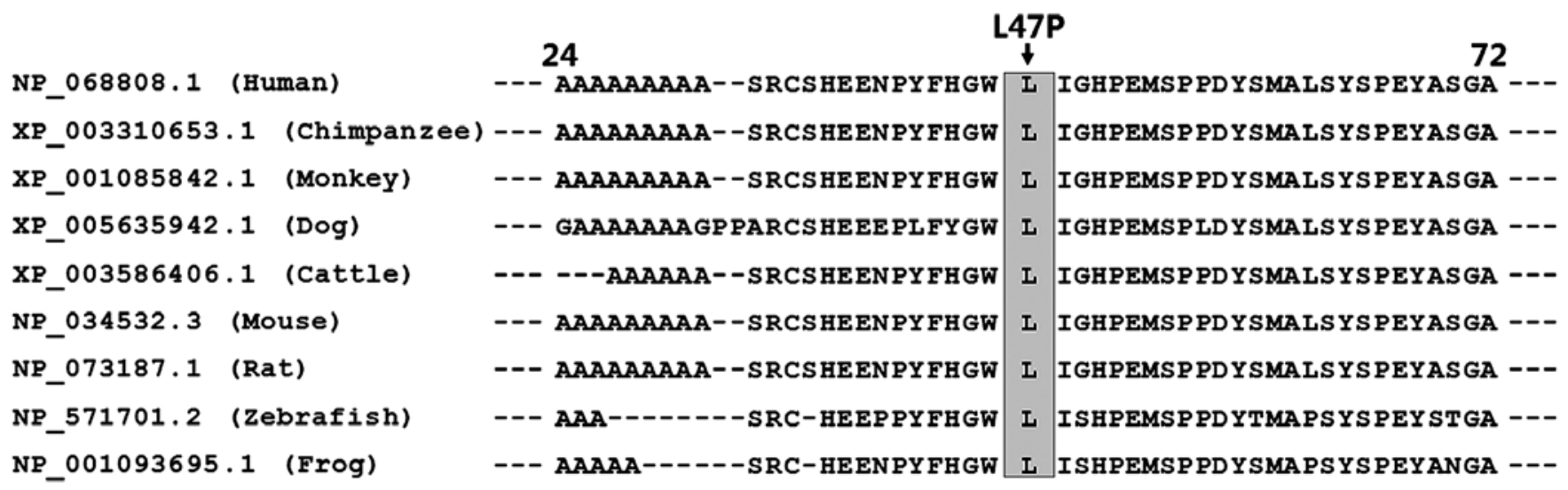

Figure 3. Multiple alignments of the amino acids of HAND2 proteins across various species. Alignment of the amino acids of human HAND2 protein with those of chimpanzee, monkey, dog, cattle, mouse, rat, zebrafish and frog displayed that the altered leucine at amino acid 47 of human HAND2 was completely conserved evolutionarily.

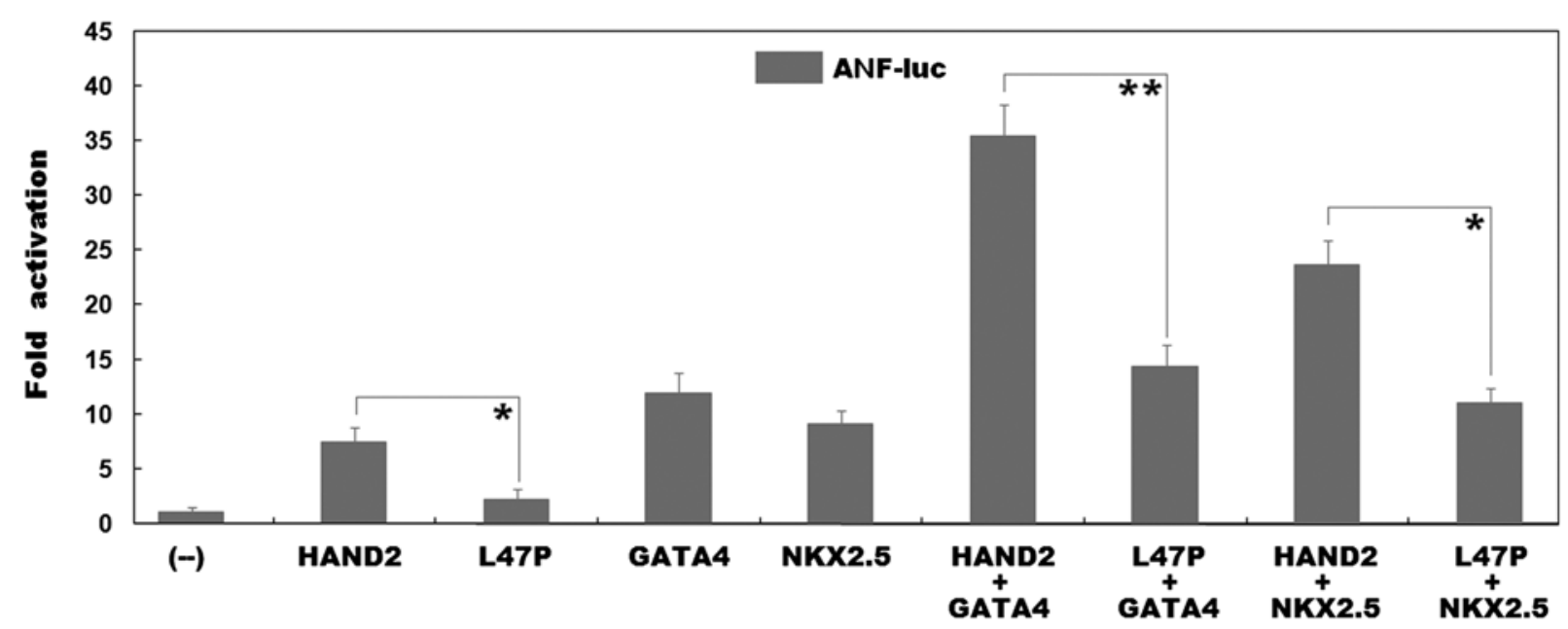

Figure 4. Functional defects of HAND2 caused by the mutation. Activation of the ANF promoter driven luciferase in HeLa cells by wild-type or L47P-mutant HAND2 (L47P), alone or in combination with GATA4 or NKX2.5, revealed significantly decreased activation or synergistic activation by the mutant protein. Experiments were performed in triplicate, and the means \pm standard deviations are shown. ${ }^{*}<0.005$ and ${ }^{* *} \mathrm{p}<0.001$ compared with the wild-type counterparts.

sponding to 3 of every 10,000 live births, with males being affected slightly more often than females (39). If not treated surgically, $25 \%$ of cases with severe obstruction succumb to the disease within the first year, $40 \%$ succumb by the age of 3 years, $70 \%$ by the age of 10 years, and $95 \%$ by the age of 40 years (39). Therefore, it is of pronounced clinical significance to ascertain the molecular basis of TOF. In the present study, a novel heterozygous mutation, p.L47P, in HAND2 was identified in a child with TOF. The missense mutation was absent in the 400 control chromosomes from a control population matched for ethnicity and gender. The mutation, which altered the amino acid conserved evolutionally across species, was predicted to be pathogenic by MutationTaster, PolyPhen-2 and SIFT. Reporter gene assays unveiled that the L47P-mutant HAND2 possessed a significantly reduced transcriptional activity. Furthermore, the L47P mutation markedly decreased the synergistic activation between HAND2 and GATA4 or HAND2 and NKX2.5. Therefore, it is possible that functionally compromised HAND2 predisposes to CHD in a subset of patients.
In humans, HAND2 is located on chromosome 4q33, with a transcript of $2.3 \mathrm{~kb}$ in length encoding a protein of 217 amino acids, and is strongly expressed in the human heart (40). The HAND2 protein harbors two functionally important structural domains, a transcriptional activation domain and a basic helix-loop-helix domain. The former is required for the transcriptional activation of downstream genes, and the latter is responsible for the binding to target DNAs and the interactions with transcriptionally cooperative partners (41). Previous studies have demonstrated that HAND2 transcriptionally activates multiple target genes highly expressed in the heart during embryogenesis, including $A N F$, alone or in synergy with such cooperative partners as GATA4, NKX2.5 and myocyte enhancer factor 2C (MEF2C) (42-45). In the present study, the mutation identified in a patient with CHD was located in the transcriptional activation domain of the HAND2 protein, and biological assays revealed that the mutation significantly diminished the transcriptional activation of the $A N F$ promoter driven by HAND2, and furthermore, the mutation markedly decreased the synergistic activation between HAND2 and 
GATA4 or HAND2 and NKX2.5, two other cardiac core transcription factors that are most commonly linked to CHD in humans (13). These findings suggest that haploinsufficiency caused by HAND2 mutation is likely an alternative mechanism underlying CHD.

The association of genetically defective Hand 2 with increased vulnerability to CHD has been substantiated in animal models. In zebrafish, Hand2-mutant embryos have been shown to have defects in myocardial development from an early stage, with a reduced number of myocardial precursors and an improperly patterned myocardial tissue, which were preceded by the aberrant morphogenesis of the cardiogenic regions of the lateral plate mesoderm (46). Additionally, gene expression profiles in Hand2-mutant embryos revealed an essential role of Hand2 in the establishment of a favorable environment for cardiac fusion through the negative regulation of fibronectin (47). In chicks, treatment of stage 8 chick embryos with Hand2 and Handl antisense oligonucleotides demonstrated that either oligonucleotide alone did not disrupt embryogenesis, whereas in combination, they inhibited cardiac development at the looping heart tube stage (33). In mice, the targeted disruption of Hand 2 has been shown to give rise to embryonic lethality on embryonic day 10.5 , mainly due to right ventricular hypoplasia and vascular deformities (34). In rescued mouse embryos by activating adrenergic receptors, the deletion of Hand 2 has been shown to lead to the misalignment of the outflow tract and aortic arch arteries, and ventricular septal defect, double outlet right ventricle, interrupted aortic artery, pulmonary stenosis, as well as retroesophageal right subclavian artery (48). Moreover, the conditional ablation of Hand2 alleles in specific cardiac cell populations at defined developmental points recapitulated the complete Hand2-null phenotype. Specifically, the loss of Hand2 at later stages of development and in restricted areas of the second heart field has been shown to cause various cardiovascular abnormalities, including hypoplastic right ventricle, tricuspid atresia, truncus arteriosus and ventricular septal defect (49). Besides, the endocardial nullification of Hand2 contributes to the abnormal development of tricuspid valve, intraventricular septum and ventricles (50). By contrast, mice with an increased copy number of Hand2, which were generated by transgene with a bacterial artificial chromosome containing Hand2, also presented with congenital heart defects (51). Taken collectively, these results suggest that Hand2 plays pivotal roles in cardiovascular morphogenesis, and the imbalanced dosage of HAND2 confers an increased predisposition to CHD.

In humans, previous studies have demonstrated that patients with chromosomal deletion or duplication that involved chromosome 4q33, the locus of $H A N D 2$, are liable to CHD, including pulmonary atresia, ventricular septal defect, coarctation of the aorta and TOF (40). In addition, HAND2 sequence variations were also discovered in patients with CHD, encompassing TOF, patent ductus arteriosus, pulmonary atresia, atrial septal defect, atrioventricular septal defect, pulmonary stenosis and double outlet right ventricle. However, the functional roles of these CHD-related mutations remain to be characterized (52).

In conclusion, to the best of our knowledge, this is the first study on the association of HAND2 loss-of-function mutation with an enhanced susceptibility to TOF in humans, providing novel insight into the molecular mechanisms responsible for the development of CHD, and implying potential implications for the xgenetic counseling of families with CHD.

\section{Acknowledgements}

We are really thankful to the study participants for their devotion to the study. This study was supported in part by grants from the key program for Basic Research of Shanghai, China (no. 14JC1405500), and the National Natural Science Fund of China (nos. 81270161 and 81470372).

\section{References}

1. Fahed AC, Gelb BD, Seidman JG and Seidman CE: Genetics of congenital heart disease: The glass half empty. Circ Res 112: 707-720, 2013.

2. Zheng JY, Tian HT, Zhu ZM, Li B, Han L, Jiang SL, Chen Y, Li DT, He JC, Zhao Z, et al: Prevalence of symptomatic congenital heart disease in Tibetan school children. Am J Cardiol 112: 1468$1470,2013$.

3. Marelli AJ, Ionescu-Ittu R, Mackie AS, Guo L, Dendukuri N and Kaouache M: Lifetime prevalence of congenital heart disease in the general population from 2000 to 2010. Circulation 130: 749-756, 2014.

4. Mozaffarian D, Benjamin EJ, Go AS, Arnett DK, Blaha MJ, Cushman M, de Ferranti S, Després JP, Fullerton HJ, Howard VJ, et al; American Heart Association Statistics Committee and Stroke Statistics Subcommittee: Heart disease and stroke statistics--2015 update: A report from the American Heart Association. Circulation 131: e29-e322, 2015.

5. Feltez G, Coronel CC, Pellanda LC and Lukrafka JL: Exercise capacity in children and adolescents with corrected congenital heart disease. Pediatr Cardiol 36: 1075-1082, 2015.

6. Williams IA, Fifer WP and Andrews H: Fetal growth and neurodevelopmental outcome in congenital heart disease. Pediatr Cardiol 36: 1135-1144, 2015.

7. Barst RJ, Ivy DD, Foreman AJ, McGoon MD and Rosenzweig EB: Four- and seven-year outcomes of patients with congenital heart disease-associated pulmonary arterial hypertension (from the REVEAL Registry). Am J Cardiol 113: 147-155, 2014.

8. Wright LK, Ehrlich A, Stauffer N, Samai C, Kogon B and Oster ME: Relation of prenatal diagnosis with one-year survival rate for infants with congenital heart disease. Am J Cardiol 113: 1041-1044, 2014.

9. Priromprintr B, Rhodes J, Silka MJ and Batra AS: Prevalence of arrhythmias during exercise stress testing in patients with congenital heart disease and severe right ventricular conduit dysfunction. Am J Cardiol 114: 468-472, 2014.

10. Ghosh RM, Gates GJ, Walsh CA, Schiller MS, Pass RH and Ceresnak SR: The prevalence of arrhythmias, predictors for arrhythmias, and safety of exercise stress testing in children. Pediatr Cardiol 36: 584-590, 2015.

11. Walsh EP: Sudden death in adult congenital heart disease: Risk stratification in 2014. Heart Rhythm 11: 1735-1742, 2014.

12. Srivastava D and Olson EN: A genetic blueprint for cardiac development. Nature 407: 221-226, 2000.

13. Andersen TA, Troelsen KL and Larsen LA: Of mice and men: Molecular genetics of congenital heart disease. Cell Mol Life Sci 71: 1327-1352, 2014.

14. Wang X, Li P, Chen S, Xi L, Guo Y, Guo A and Sun K: Influence of genes and the environment in familial congenital heart defects. Mol Med Rep 9: 695-700, 2014.

15. Qu XK, Qiu XB, Yuan F, Wang J, Zhao CM, Liu XY, Zhang XL, Li RG, Xu YJ, Hou XM, et al: A novel NKX2.5 loss-of-function mutation associated with congenital bicuspid aortic valve. Am J Cardiol 114: 1891-1895, 2014.

16. Wang X, Ji W, Wang J, Zhao P, Guo Y, Xu R, Chen S and Sun K: Identification of two novel GATA6 mutations in patients with nonsyndromic conotruncal heart defects. Mol Med Rep 10: 743-748, 2014.

17. Al Turki S, Manickaraj AK, Mercer CL, Gerety SS, Hitz MP, Lindsay S, D'Alessandro LC, Swaminathan GJ, Bentham J, Arndt AK, et al: UK10K Consortium, Wilson DI, Mital S and Hurles ME: Rare variants in NR2F2 cause congenital heart defects in humans. Am J Hum Genet 94: 5745-5785, 2014. 
18. Zhao L, Ni SH, Liu XY, Wei D, Yuan F, Xu L, Xin-Li, Li RG, $\mathrm{Qu} \mathrm{XK}, \mathrm{Xu}$ YJ, et al: Prevalence and spectrum of Nkx2.6 mutations in patients with congenital heart disease. Eur J Med Genet 57: 579-586, 2014.

19. Werner P, Paluru P, Simpson AM, Latney B, Iyer R, Brodeur GM and Goldmuntz E: Mutations in NTRK3 suggest a novel signaling pathway in human congenital heart disease. Hum Mutat 35 : $1459-1468,2014$

20. Wei D, Gong XH, Qiu G, Wang J and Yang YQ: Novel PITX2c loss-of-function mutations associated with complex congenital heart disease. Int J Mol Med 33: 1201-1208, 2014.

21. Cowan J, Tariq M and Ware SM: Genetic and functional analyses of ZIC3 variants in congenital heart disease. Hum Mutat 35 $66-75,2014$.

22. Shi LM, Tao JW, Qiu XB, Wang J, Yuan F, Xu L, Liu H, Li RG, $\mathrm{Xu}$ YJ, Wang Q, et al: GATA5 loss-of-function mutations associated with congenital bicuspid aortic valve. Int J Mol Med 33: 1219-1226, 2014.

23. Huang RT, Xue S, Xu YJ, Zhou M and Yang YQ: Somatic GATA5 mutations in sporadic tetralogy of Fallot. Int J Mol Med 33: 1227-1235, 2014

24. Racedo SE, McDonald-McGinn DM, Chung JH, Goldmuntz E, Zackai E, Emanuel BS, Zhou B, Funke B and Morrow BE: Mouse and human CRKL is dosage sensitive for cardiac outflow tract formation. Am J Hum Genet 96: 235-244, 2015.

25. Pan Y, Geng R, Zhou N, Zheng GF, Zhao H, Wang J, Zhao CM, Qiu XB, Yang YQ and Liu XY: TBX20 loss-of-function mutation contributes to double outlet right ventricle. Int J Mol Med 35: 1058-1066, 2015

26. McCulley DJ and Black BL: Transcription factor pathways and congenital heart disease. Curr Top Dev Biol 100: 253-277, 2012.

27. Vincentz JW, Barnes RM and Firulli AB: Hand factors as regulators of cardiac morphogenesis and implications for congenital heart defects. Birth Defects Res A Clin Mol Teratol 91: 485-494, 2011.

28. Reamon-Buettner SM, Ciribilli Y, Inga A and Borlak J: A loss-of-function mutation in the binding domain of HAND1 predicts hypoplasia of the human hearts. Hum Mol Genet 17: $1397-1405,2008$

29. Reamon-Buettner SM, Ciribilli Y, Traverso I, Kuhls B, Inga A and Borlak J: A functional genetic study identifies HAND1 mutations in septation defects of the human heart. Hum Mol Genet 18: 3567-3578, 2009.

30. Cheng Z, Lib L, Li Z, Liu M, Yan J, Wang B and Ma X: Two novel HAND1 mutations in Chinese patients with ventricular septal defect. Clin Chim Acta 413: 675-677, 2012.

31. Thomas T, Yamagishi H, Overbeek PA, Olson EN and Srivastava D: The bHLH factors, dHAND and eHAND, specify pulmonary and systemic cardiac ventricles independent of leftright sidedness. Dev Biol 196: 228-236, 1998.

32. Thattaliyath BD, Livi CB, Steinhelper ME, Toney GM and Firulli AB: HAND1 and HAND2 are expressed in the adultrodent heart and are modulated during cardiac hypertrophy. Biochem Biophys Res Commun 297: 870-875, 2002.

33. Srivastava D, Cserjesi P and Olson EN: A subclass of bHLH proteins required for cardiac morphogenesis. Science 270 : 1995-1999, 1995.

34. Srivastava D, Thomas T, Lin Q, Kirby ML, Brown D and Olson EN: Regulation of cardiac mesodermal and neural crest development by the bHLH transcription factor, dHAND. Nat Genet 16: 154-160, 1997.

35. McFadden DG, Barbosa AC, Richardson JA, Schneider MD, Srivastava D and Olson EN: The Hand1 and Hand2 transcription factors regulate expansion of the embryonic cardiac ventricles in a gene dosage-dependent manner. Development 132: 189-201, 2005.
36. Wang XH, Huang CX, Wang Q, Li RG, Xu YJ, Liu X, Fang WY and Yang YQ: A novel GATA5 loss-of-function mutation underlies lone atrial fibrillation. Int J Mol Med 31: 43-50, 2013.

37. Wei D, Bao H, Zhou N, Zheng GF, Liu XY and Yang YQ: GATA5 loss-of-function mutation responsible for the congenital ventriculoseptal defect. Pediatr Cardiol 34: 504-511, 2013.

38. Zhang XL, Dai N, Tang K, Chen YQ, Chen W, Wang J, Zhao CM, Yuan F, Qiu XB, Qu XK, et al: GATA5 loss-of-function mutation in familial dilated cardiomyopathy. Int J Mol Med 35: 763-770, 2015.

39. Starr JP: Tetralogy of fallot: Yesterday and today. World J Surg 34: 658-668, 2010 .

40. Russell MW, Kemp P, Wang L, Brody LC and Izumo S: Molecular cloning of the human HAND2 gene. Biochim Biophys Acta 1443: 393-399, 1998

41. Dai YS and Cserjesi P: The basic helix-loop-helix factor, HAND2, functions as a transcriptional activator by binding to E-boxes as a heterodimer. J Biol Chem 277: 12604-12612, 2002.

42. Dai YS, Cserjesi P, Markham BE and Molkentin JD: The transcription factors GATA4 and dHAND physically interact to synergistically activate cardiac gene expression through a p300-dependent mechanism. J Biol Chem 277: 24390-24398, 2002.

43. Thattaliyath BD, Firulli BA and Firulli AB: The basic-helixloop-helix transcription factor HAND2 directly regulates transcription of the atrial naturetic peptide gene. J Mol Cell Cardiol 34: 1335-1344, 2002.

44. Zang MX, Li Y, Wang H, Wang JB and Jia HT: Cooperative interaction between the basic helix-loop-helix transcription factor dHAND and myocyte enhancer factor $2 \mathrm{C}$ regulates myocardial gene expression. J Biol Chem 279: 54258-54263, 2004.

45. Zang MX, Li Y, Xue LX, Jia HT and Jing H: Cooperative activation of atrial naturetic peptide promoter by dHAND and MEF2C. J Cell Biochem 93: 1255-1266, 2004.

46. Yelon D, Ticho B, Halpern ME, Ruvinsky I, Ho RK, Silver LM and Stainier DY: The bHLH transcription factor hand2 plays parallel roles in zebrafish heart and pectoral fin development. Development 127: 2573-2582, 2000.

47. Garavito-Aguilar ZV, Riley HE and Yelon D: Hand2 ensures an appropriate environment for cardiac fusion by limiting Fibronectin function. Development 137: 3215-3220, 2010.

48. Morikawa Y and Cserjesi P: Cardiac neural crest expression of Hand 2 regulates outflow and second heart field development. Circ Res 103: 1422-1429, 2008.

49. Tsuchihashi T, Maeda J, Shin CH, Ivey KN, Black BL, Olson EN, Yamagishi $\mathrm{H}$ and Srivastava D: Hand2 function in second heart field progenitors is essential for cardiogenesis. Dev Biol 351: 62-69, 2011.

50. VanDusen NJ, Casanovas J, Vincentz JW, Firulli BA, Osterwalder M, Lopez-Rios J, Zeller R, Zhou B, Grego-Bessa J, De La Pompa JL, et al: Hand2 is an essential regulator for two Notch-dependent functions within the embryonic endocardium. Cell Rep 9: 2071-2083, 2014

51. Tamura M, Hosoya M, Fujita M, Iida T, Amano T, Maeno A, Kataoka T, Otsuka T, Tanaka S, Tomizawa S, et al: Overdosage of Hand 2 causes limb and heart defects in the human chromosomal disorder partial trisomy distal 4q. Hum Mol Genet 22: 2471-2481, 2013.

52. Shen L, Li XF, Shen AD, Wang Q, Liu CX, Guo YJ, Song ZJ and Li ZZ: Transcription factor HAND2 mutations in sporadic Chinese patients with congenital heart disease. Chin Med J (Engl) 123: 1623-1627, 2010 